structure and function of neurotransmitter receptors could have been discussed in more detail, given their central role in synaptic transmission. Also, an overview of synaptic transmission in neurological and psychiatric disease would have broadened the book's appeal. Synapses nevertheless remains an impressive book that will be a useful reference to neuroscientists at all levels and a potential tool for teaching graduate students and advanced undergraduates.

Michael D. Ehlers and Guoping Feng are in the Department of Neurobiology, Duke University Medical Center, Box 3209, Durham,

North Carolina 27710, USA.

\title{
Betwixt and between
}

\section{Liquid Crystals: Experimental Study of Physical Properties and Phase Transitions \\ edited by Satyendra Kumar \\ Cambridge University Press: 2000. 483 pp. $\mathfrak{E} 70, \$ 110$}

\section{John Lydon}

Any discussion of liquid-crystalline phases usually starts by describing them as a state of matter that is intermediate in structure between the more-or-less totally ordered crystalline solid phase and the completely disordered state of a liquid. This is a perfectly valid statement, but it carries all the wrong connotations: it implies that the properties of these 'mesophases' will also be intermediate. Admittedly, in some cases this is true. But in general, the combination of fluidity and spontaneous molecular ordering gives rise to unique and remarkable phenomena.

The liquid-crystal phases have, with good reason, been called nature's 'sensitive' phases. In fact, they are sensitive to virtually everything. Some change colour with temperature (and are sensitive to one-hundredth of a degree). Others respond to small electric fields and are readily aligned on treated surfaces, a combination of properties that makes them uniquely useful for display devices. Others form solvent phases that can align dissolved solute molecules, and this phenomenon is utilized in display devices and in new forms of spectroscopy. It is also possible to produce highly ordered, ultrastrong materials, notably Kevlar, by spinning fibres from liquid-crystalline polymer melts (rather than disordered liquids).

These unique characteristics are, of course, an expression of measurable physical properties, and over the past 20 years or so techniques for measuring them have featured increasingly in the research literature. The "long felt need" identified by Satyendra Kumar "for a source of general, non-super-

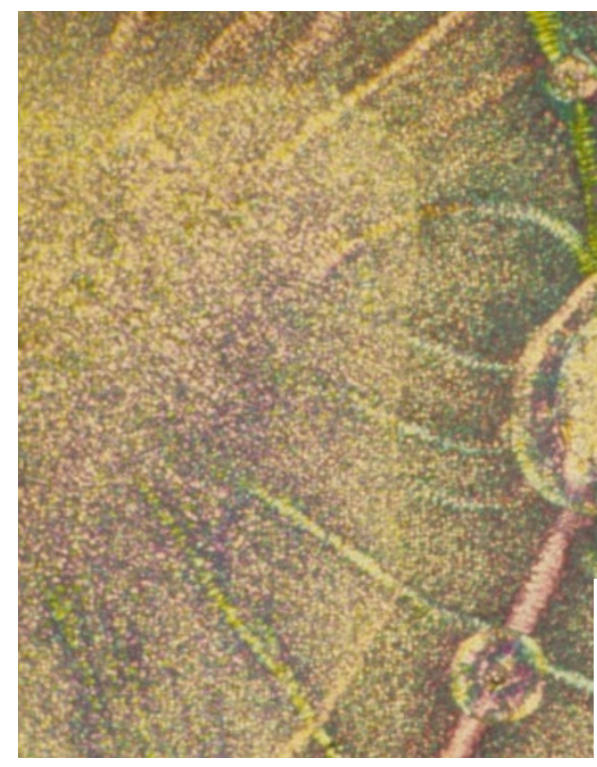

Fluid functions: liquid crystals examined by light (right) and polarizing (top) microscopy.

fluous and practical information regarding the experimental research techniques and how they are applied to liquid crystals" is real enough, and the book he has put together is most welcome.

Liquid Crystals competently and elegantly covers the principal techniques used to investigate liquid crystals - these include polarizing microscopy, differential scanning calorimetry, X-ray diffraction, nuclear magnetic resonance and light scattering. And the chapter on physical properties covers all the familiar themes - dielectric properties, optical diamagnetic elastic and viscous properties, electrical and thermal conductance and density measurement with 20 pages of colour plates showing the main optical textures. There is a remarkable chapter on freely suspended films - films stretched across a hole in a plate so that they are not in contact with the solid surface on either side. And the book ends with a discussion of the relationship between chemical structure and mesogenic properties. Each topic receives a mathematical treatment, at a level comprehensible to a physics graduate.

The patchwork of chapters by a dozen authors is almost inevitably selective and idiosyncratic, and in many places the book has depth but not breadth. Esoteric points are sometimes discussed in detail. For example, the authors from Ohio's Kent State University are proud of their characterization of the elusive biaxial nematic phase and could not resist mentioning it in the introduction. But there is virtually nothing about lyotropic phases, polymer liquid crystals or discotics. Nevertheless, Kumar has achieved his goal of producing a volume of practical information with "in-depth technical details". For students about to embark on experimental investigations of thermo-
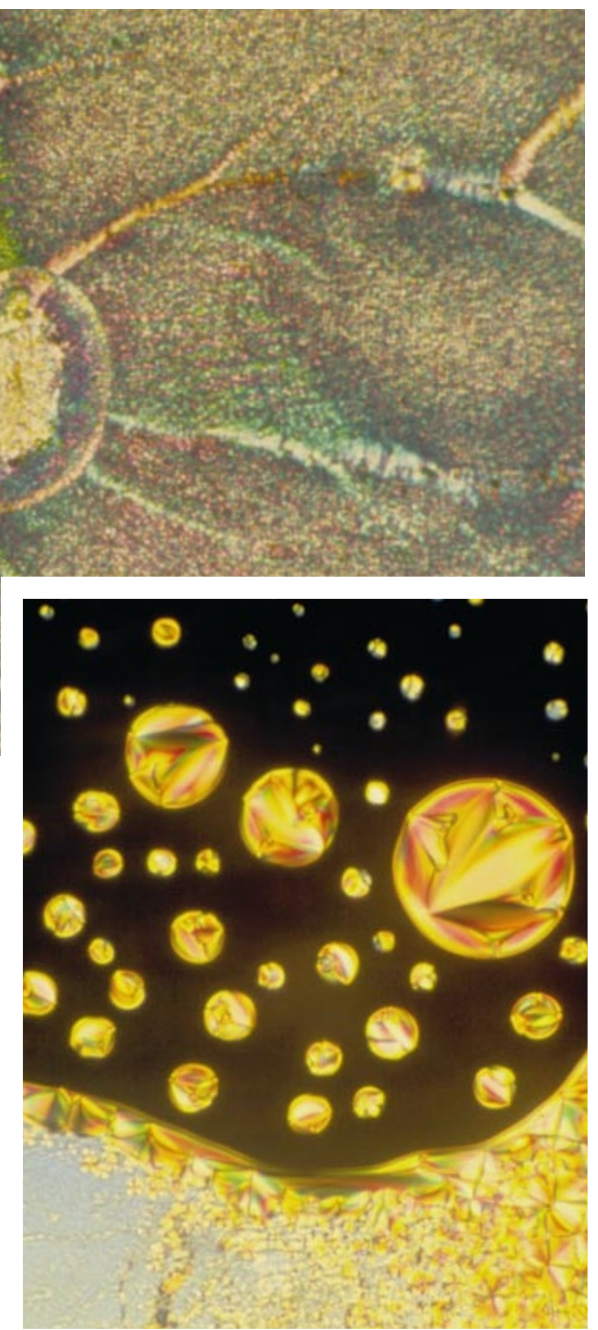

tropic, nematic or smectic systems, this book could be one of their best buys.

John Lydon is in the Department of Biochemistry and Molecular Biology, University of Leeds,

Leeds LS2 9TJ, UK.

\section{Flitting around the subject}

\section{Fly: An Experimental Life}

by Martin Brookes

Weidenfeld \& Nicolson: 2001. 215 pp. 16.99

\section{Peter Lawrence}

It is a 'truth' universally acknowledged that in any popular piece of science writing or television, the science must be diluted with entertaining asides. Otherwise, it is feared, the reader will doze off in her chair and the viewer change channel. Martin Brookes appears to have embraced this belief when he set out to write about the fruitfly Drosophila, about the history of research using it, and about the fly's place in our present understanding of biology. Naturally, he has to communicate some facts and ideas. He fears, however, that his readers will find science a bore, so he offers us 


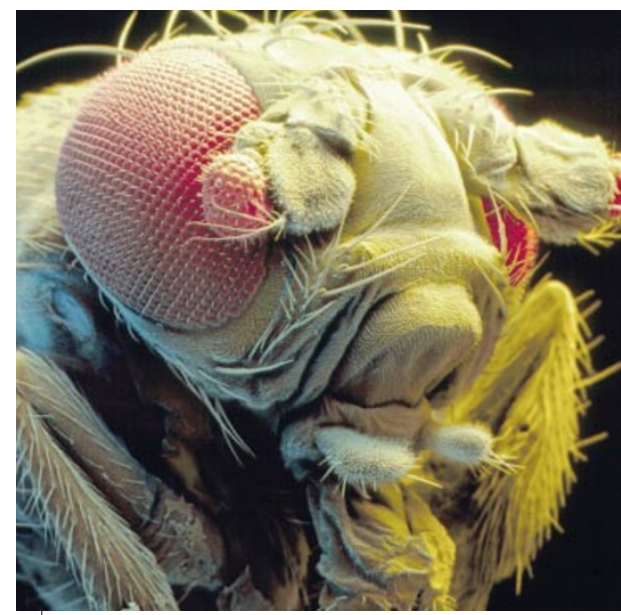

Fruits of experiment: a mutant fly with two small extra eyes in place of antennae.

little holidays from the hard work as we go along. The result? A book written as if by a distrait and garrulous aunt who cannot stick to the point for more than a few seconds - it fizzes with the insubstantial.

Brookes sets the scene with the prose of a fancy menu. Do flies feed? No - "their digestive juices work chemical magic on a belly full of banana goo". Imagination unleashed, he then gives us a sketch of T. H. Morgan, the greatest of all developmental geneticists, whose wiry beard contained "a morsel of rotting banana ensnared in the hooks of his facial hair". Then something a bit more substantial - a discursive minibiography of Morgan and a picture of his world, apparently using Garland Allen's fine biography, Thomas Hunt Morgan: The Man and his Science (now, sadly, out of print), as the source; this is informative and interesting. There are titbits about Morgan's life with sea spiders and worms, and how he met the fruitfly - as well as his wife.

Brookes has a lively tabloid style and can sometimes be sharp and even unfair - as in his summary of Lamarck's theory of evolution: "It was all very complicated. It was also complete garbage." He does better when he sticks to a theme. Morgan's discovery of the white mutation and how he deduced its location on the X chromosome is well described.

The heart of this brief book is a set of unrelated chapters that sample some of the topics that Drosophila has illuminated. "Unscrambling the egg" is about the fly's huge contribution to our knowledge of development. Here Brookes continues to entertain, but his writing betrays a lack of understanding of the subject, which gives the whole a very second-hand feel.

He then turns his attention to evolutionary genetics and, in particular, to the life and contributions of Theodosius Dobzhansky. He clearly knows much more about this subject and could have conveyed more understanding. But he cannot stick to a storyline, and all of us - author, reader, Dobzhansky and Morgan - are picked up and spun around like dust in a desert whirligig. Next comes behavioural genetics, where Brookes appears to have depended largely on Jonathan Weiner's lyrical book Time, Love, Memory (Knopf, 1999). And just in case he might be accused of getting heavy, we have short and spicy chapters on sex, ageing and speciation.

But the important question is: who is this book for? Not for the likes of me, perhaps, for I have grown accustomed to the little faces of fruitflies. So I gave it to a first-year biology undergraduate. She read the book quickly and easily, and liked its lively narrative style - a definite plus there. But she also wondered who would want to read it. Not her, she felt: when the material covered was central and important, it did not inform but rather perplexed. For example, having been taught the basis of Mendel's ratios in school, she found Brookes's analogy of mating houses with black and white doors confusing. And when the information was more peripheral, such as a summary of Ulrike Heberlein's approach to alcohol addiction using flies, she thought that the attempt to be hip and happening meant that the message itself got lost.

So my friend was amused rather than informed; perhaps this is not too bad, for she might now go and look for more information in heavier texts. Nevertheless, a scientific story can be exciting; history and logic alone can engage a reader, and I think Brookes would have done better had he explained more and embellished less. All the work on Drosophila over the past 100 years has provided much to help us understand ourselves and nature; but we still await a good popular book that explains just how. Peter Lawrence is at the MRC Laboratory of Molecular Biology, University Medical School, Hills Road, Cambridge CB2 2QH, UK.

\section{Chemical reflections}

\section{Miroir de la Chimie}

by Pierre Laszlo

Seuil: 2000. 328 pp. 21.04 euros

\section{Jacques Reisse}

The organic chemist Pierre Laszlo writes extremely well, with a rare elegance. Miroir de la Chimie is a collection of short essays, in French, on a wide range of topics related to chemistry that will interest both the professional chemist and the non-chemist. The patchwork format and the arbitrary grouping of the essays into 'themed' chapters are a little off-putting at first, but if you treat the book as something to dip into, reading it becomes a real pleasure. Laszlo presents a succession of glimpses into various aspects of chemistry and into the lives and activities of chemists, from obscure postdocs to Nobel prizewinners.

You might start with one of the essays in the first chapter - "Six faces of the molecular object" - but could equally well begin with "Six characters: a portrait gallery", "Six themes: the chemical theatre", or "Six instants in the research career". The concluding "Bibliographic Essay" provides much useful information not only for the non-specialist but also for teachers of chemistry.

One of the book's great strengths is the fact that the information provided is accurate and well documented. Laszlo is a careful observer of the scientific community to which he belongs and describes it perceptively but without malice. During his career, he has worked with or met some of the most prominent chemists in structural chemistry and stereochemistry. And over the past 40 years he has accumulated a rich hoard of observations not only about chemistry and its developments but also about chemists themselves and the social group that they make up. Like all human societies, this one has its characteristics, rules, intellectual leaders and many obscure workers, and Laszlo makes it come alive for us in all its colourful variety.

Laszlo knows that chemistry has a poor public image but he also knows how important it is to the world. He makes an impressive attempt to convince the reader of this, and deserves to succeed. One of his strategies here is a short but convincing piece of science fiction that describes what might happen if a large meteorite hit the Earth near the Gulf of Mexico, the site of many US petrochemical plants.

The book is really very good. It gives the non-chemist a realistic view of the chemical sciences and describes how the community works, how chemists interact with one another, how some of them achieve success, and the many chemists who have contributed, at different levels, to the dramatic development of the field. Laszlo's book will also be appreciated by the chemistry community, particularly those interested in the history of their discipline, the role of leaders in the field, and the impact of major books, prestigious conferences and scientific prizes on the evolution of chemistry during the second half of the last century. Jacques Reisse is at Chimie Organique (CP 165/64), Université Libre de Bruxelles, 50 Avenue F. D. Roosevelt, B-1050 Bruxelles, Belgium.

\section{Correction}

The photograph on page 519 of the 29 March issue (from the book Glorious Eclipses) depicts the Blue Mosque (Sultan Ahmet Mosque) in Istanbul and not Hagia Sofia as noted in the book and in our caption. 